\title{
Reliability Optimization Design of Submarine Free-Running Model Systems
}

\author{
Yang Jianjun and Li Wenjin
}

\begin{abstract}
With regard to the reliability design of submarine free-running model system, this paper puts forward a focused design method for optimization of reliability. After constructing a matrix task profile, the reliability modeling theory of phased mission system is employed to build a system reliability model, and the measures for technical improvement are brought forward according to the results of FMEA analysis. Reliability redundancy optimization model is established based on volume, weight and cost and solved by using particle swarm optimization. A case is presented to illustrate the effectiveness and reliability of optimization design.
\end{abstract}

Index Terms-Submarine free-running model, reliability optimization, phased mission system, redundancy design.

\section{INTRODUCTION}

Submarine free-running model is a test platform featured by high safety, operability, vivid simulation of flow field, reasonable change of working condition, and some other benefits, so it plays a very significant role in the study on the performance of various submarines. After USS Albacore (AGSS-569) submarine, the United States has always employed the free-running model for submarine tests and studies on simulation of submarine properties. Along with the development of submarine technology, free-running model system becomes more and more complicated, and there are higher and higher requirements for reliability. The quality of reliability design directly determines whether the design of submarine free-running model test system is successful.

Submarine free-running model test contains sailing and other phases, which require different equipment, so it is a typical phased mission system [1]. Since the study on phased mission system reliability [2] was proposed in 1975, it has always been the focus in the field of system reliability. Now, there are already some researches on the reliability optimization of phased mission systems of different types [3-5]. This paper will regard submarine free-running model system as a non-repairable phased mission system to analyze the missions and structure of submarine free running model test system. After constructing a mission profile, analyzing the weak units and conducting technical improvement and redundancy improvement of the system, this paper brings

Manuscript received December 9, 2014; revised April 23, 2015

Yang Jianjun is with Navy University of Engineering, Wuhan, 430033, China (e-mail: 13871263309@163.com).

Li Wenjin is with Management Science and Engineering, Navy University of Engineering, Wuhan, 430033, China (e-mail: liwenjin2012@163.com). forward a reliability optimization design method for submarine free-running model system, so as to effectively improve the reliability of system.

\section{StUdy ON RELIABILITY OPTIMIZATION METHOD}

\section{A. Basic Idea of Free-Running Model Reliability Optimization}

The basic procedure of reliability optimization design for a submarine free-running model system is as follows: 1). Analyze system reliability design, construct mission profile and reliability block diagram and estimate system reliability; 2). If the estimated reliability does not satisfy the requirements, carry out the reliability optimization design for the system; 3). Perform FMECA analysis on the system to find out the weak units of the system, conduct technical improvement toward the weak units causing low reliability in the system design, and then estimate the reliability of system again; 4). If the reliability is still unacceptable, carry out redundancy optimization toward the weak units of the system till system reliability falls into the specified range of constraints (system cost, system volume and system weight) and satisfies the requirements. The whole procedure is presented in Fig. 1.

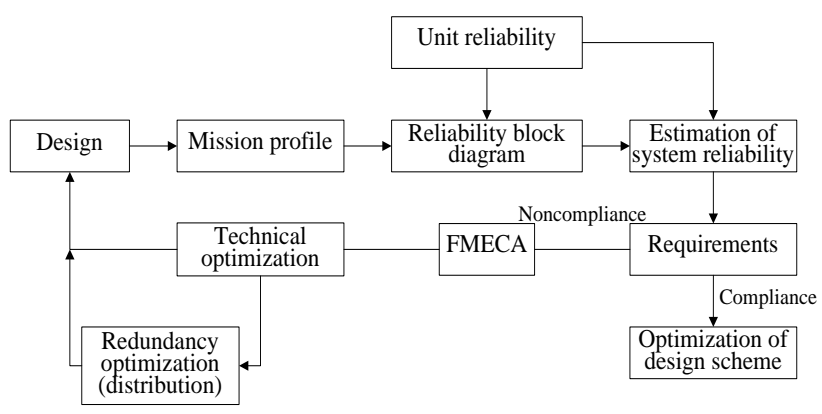

Fig. 1. Basic idea of reliability optimization of submarine free-running model system.

\section{B. Free-Running Model Reliability Optimization Steps}

According to the basic procedure of reliability optimization design, the following steps are arranged for free-running reliability optimization:

Step 1. Construct the mission profile of free-running model system. Mission profile refers to the time sequence description of events and environments experienced when the system completes the specified mission [6]. When constructing the mission profile of free-running model system, matrix mission profile can be employed. The schematic diagram of mission profile for a submarine free-running model system is presented in Table I. 
Step 2. Construct the reliability model of free-running model system. Free-running model system is a phased mission system, so the reliability modeling theory for such type of system can be employed to build a system reliability model in the form of block diagram.

Step 3. Estimate the reliability of free-running model system. By building the mathematic model for system reliability, it is able to estimate system reliability. The estimation helps find out whether system reliability satisfies the requirements and whether reliability optimization is required.

TABLE I: Mission PRofiLe of SubMARINE FrEE-RunNing MOdEL

\begin{tabular}{lccc}
\multicolumn{3}{c}{ SYSTEM } \\
\hline \hline \multicolumn{1}{c}{ Mission Phase } & $\begin{array}{c}\text { Course-keepin } \\
\mathrm{g} \text { Test }\end{array}$ & $\begin{array}{c}\text { Load } \\
\text { Rejection Test }\end{array}$ & Brake Test \\
\hline $\begin{array}{l}\text { Phase Duration } \\
\text { Batteries }\end{array}$ & $55 \mathrm{~s}$ & $20 \mathrm{~s}$ & $55 \mathrm{~s}$ \\
Propeller & $\mathrm{X}$ & $\mathrm{X}$ \\
AC ServoDrive & & $\mathrm{X}$ \\
Inverter & & $\mathrm{X}$ \\
$\begin{array}{l}\text { High-pressure Gas } \\
\text { Cylinder }\end{array}$ & & $\mathrm{X}$ \\
\hline \hline
\end{tabular}

Note: In the matrix, the columns present the mission phases of system and the lines contain the description of environment and the description of working state of equipment in each mission phase. If left blank at the intersection of mission phase and equipment, it means that the equipment operates in the mission phase. If it is filled with $\mathrm{X}$, it means that the equipment does not operate in the mission phase.

Step 4. FMECA analysis. FMECA (failure mode, effect and criticality analysis)[7] analyzes all possible failure modes and their causes and consequences to find out the weak units in system equipment, in order to carry out the optimization design of system toward such weak units and improve the reliability of system. The instructions for FMECA are detailed in Reference [8].

If it is estimated that system reliability does not satisfy the requirements, it is necessary to perform FMECA analysis on the system and find out the weak units of the system, so as to conduct technical improvement and redundancy optimization in the focused manner and improve system reliability to the requirements.

Step 5. Technical improvement. Technical improvement means to select more reasonable technology according to the technical problems in the system design when any weak unit of the system causes lower system reliability due to improper reliability design of the system, so as to technically improve the system and enhance its reliability.

Step 6. Redundancy Optimization. Redundancy refers to the maintenance of redundant resources. When a system or its equipment fails, the failed part can be replaced by the redundant part, in order to guarantee the normal completion of specified function as scheduled. Redundancy optimization means to select one or several modes of redundancy based on the features and properties of system and add the redundant parts, in order to achieve the ideal reliability of the system [9].

Redundancy optimization focuses on the failure of system reliability to satisfy the requirements after technical improvement, and optimizes the redundancy of the system. When technical improvement fails to enhance the reliability of system, redundant units can be added to any weak unit whose lower reliability leads to the low reliability of system and improve the reliability of weak units, so as to enhance system reliability.

Step 7. Judge whether system reliability satisfies the requirements after technical improvement and redundancy optimization. If satisfying the requirements, the system with optimized reliability is confirmed as the final design scheme for system reliability. If not, optimization must be adjusted.

\section{CASE ANALYSIS}

\section{A. Reliability Design Analysis}

A submarine free-running model does not receive systematic reliability design, so its system reliability fails to satisfy the requirements of testing program and severely obstructs the test and study of the submarine free-running model system. As test period is delayed, its cost increases constantly. Therefore, it is analyzed in this paper.

\section{1) Mission profile}

A mission profile is constructed based on the reliability design analysis of the submarine free-running model system, as shown in Fig. 2. Due to limited space, this paper will present the mission profile of drive subsystem for only three mission phases in the submarine free-running model system. In practice, it is necessary to fully describe the environment parameters and working state of each equipment in each phase among 13 mission phases including course-keeping and 7 subsystems including drive subsystem, in order to construct their integrated mission profiles. More details are given in Reference [10].

\section{2) Reliability modeling and estimation}

According to the mission profile of the submarine free-running model system, a system reliability block diagram is constructed to analyze the functional relations between equipment during the design of system reliability, in order to provide the theoretical basis for constructing the mathematic model of its reliability and estimating the reliability of system.

A submarine free-running system contains 13 mission phases, so it should be constructed by following the phased mission theory. The reliability block diagrams for three mission phases of free-running model system are presented for illustration in Fig. 2-Fig. 4.

The reliability block diagrams of the submarine free-running model are analyzed to build its mathematic model of reliability, and the unit reliability parameters given by experts are utilized to calculate the reliability of the submarine free-running model system. The estimation is detailed in Reference [10]. The calculated reliability of this system is 0.753 , which does not satisfy the requirements. As revealed in the practical test, the test period is changed from $15 \mathrm{~d}$ to $45 \mathrm{~d}$ due to low reliability, which is very hazardous. Hence, reliability optimization is designed for this system to improve its reliability.

\section{3) FMECA analysis}

The FMECA analysis process of AC servo drive in the system is illustrated in Table II. As revealed in this analysis 
process, the severity of AC servo drive is Level I.

FMECA analysis is carried out for all equipment units in the system to identify the equipment with high level of criticality as the weak units of the system, including AC servo drive, water tank (also known as attitude control), acoustic positioning system, water pump, batteries, high-pressure gas cylinder, water inlet (outlet) controller, exhaust controller and pressure sensor, etc.

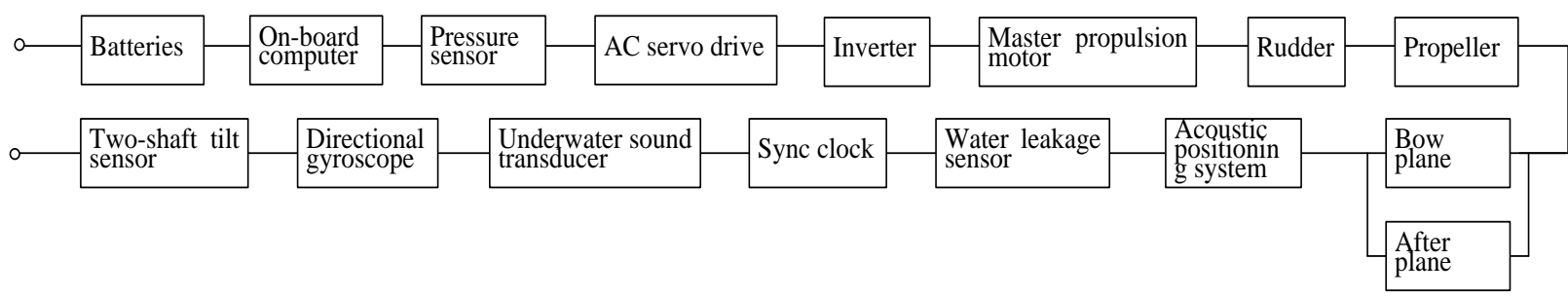

Fig. 2. Reliability block diagram of course-keeping test.

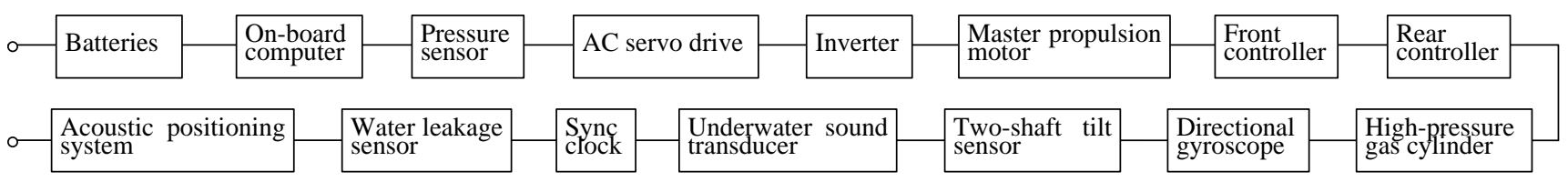

Fig. 3. Reliability block diagram of load rejection test.

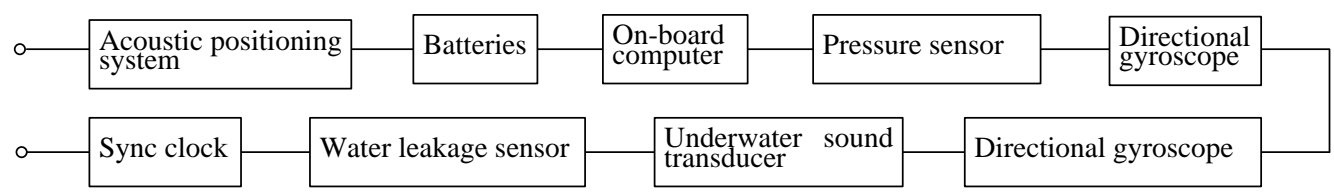

Fig. 4. Reliability block diagram of brake system.

TABLE II: FMECA ANALYSIS OF AC SERVO DRIVE

\begin{tabular}{|c|c|c|c|c|c|c|c|c|c|c|c|}
\hline \multirow{2}{*}{ System } & \multirow{2}{*}{$\begin{array}{l}\text { Product or } \\
\text { Feature } \\
\text { Description }\end{array}$} & \multirow[t]{2}{*}{ Function } & \multirow{2}{*}{$\begin{array}{l}\text { Failure } \\
\text { Mode }\end{array}$} & \multirow[t]{2}{*}{ Cause } & \multirow{2}{*}{$\begin{array}{c}\text { Mission } \\
\text { Phase and } \\
\text { Work } \\
\text { Mode }\end{array}$} & & \multicolumn{2}{|c|}{ Failure Effect } & \multirow{2}{*}{$\begin{array}{c}\text { Probability } \\
\text { Level }\end{array}$} & \multirow{2}{*}{$\begin{array}{c}\text { Criticality } \\
\text { Level }\end{array}$} & \multirow[t]{2}{*}{ Severity Leve } \\
\hline & & & & & & $\begin{array}{l}\text { Local } \\
\text { Effect }\end{array}$ & $\begin{array}{c}\text { Higher } \\
\text { Level }\end{array}$ & Final Effect & & & \\
\hline $\begin{array}{l}\text { Drive } \\
\text { system }\end{array}$ & $\begin{array}{c}\text { AC servo } \\
\text { drive }\end{array}$ & $\begin{array}{c}\text { For } \\
\text { frequency } \\
\text { conversion }\end{array}$ & $\begin{array}{c}\text { Error in } \\
\text { frequency } \\
\text { conversio } \\
\mathrm{n}\end{array}$ & $\begin{array}{l}\text { Electromagnetic } \\
\text { interference } \\
\text { generated by } \\
\text { inverter }\end{array}$ & $\begin{array}{l}\text { Sailing, } \\
\text { operation } \\
\text { and return }\end{array}$ & $\begin{array}{l}\text { Failure of } \\
\text { frequency } \\
\text { conversion }\end{array}$ & $\begin{array}{l}\text { Failure of } \\
\text { execution } \\
\text { mechanism }\end{array}$ & $\begin{array}{c}\text { Failure of } \\
\text { submarine } \\
\text { free-running } \\
\text { model }\end{array}$ & A & 1 & I \\
\hline
\end{tabular}

\section{B. Reliability Optimization}

\section{1) Technical improvement}

The technical improvement of the submarine free-running model system is analyzed as follows:

AC servo drive is used for frequency conversion in the system. However, the submarine free-running model system employs batteries to supply the power for AC servo drive. As batteries supply the direct current, it is necessary to convert the direct current into alternating current through inverter. As inverter may generate strong electromagnetic interference during operation, it affects the normal operation of some equipment in the system and causes the low reliability of system. This is caused by electromagnetic compatibility. Thus, DC servo drive is used to replace AC servo drive in this system, so inverter can be removed to eliminate the problem of electromagnetic compatibility and enhance the reliability of system. The test has proven the feasibility and effectiveness of such technical improvement.

In this system, four water tanks are used to adjust the attitude deviation of free-running model during navigation by controlling their water level. In the practical test, it is very difficult to appropriately control the water level due to insufficient accuracy of judgment. Thus, only two out of 16 water levels, that is, draining and filling, can be realized to adjust the navigation attitude of free-running model in the system reliability design. Therefore, the system reliability is quite low. This is caused by improper selection of equipment. Based on the torque principle, the controller with a $100 \mathrm{~kg} \times 1 \mathrm{~m}$ horizontal torque and a $40 \mathrm{~kg} \times 0.2 \mathrm{~m}$ vertical torque is designed in the submarine free-running model to replace water tanks for adjusting navigation attitude. A pressure sensor is used to control the adjustment sizes of two torques to the accuracy of millimeter, so as to improve the accuracy of judgment. The test has proven that this optimization guarantees the accuracy of free-running model navigation attitude and enhances the reliability of submarine free-running model system.

Acoustic positioning device can monitor the navigation state of free-running model. During test, every acoustic positioning device can monitor a range of 75 degrees, so it may easily overlook some areas and is unable to monitor whether free-running model goes beyond the specified testing waters. This lowers the reliability of free-running 
model. This is caused by selection of equipment. Thus, 360-degree acoustic positioning devices can replace these devices and an emergency acoustic positioning system is added to monitor whether free-running model goes beyond the specified testing waters. When it goes beyond the specified testing waters, emergency surfacing function will be immediately triggered.

TABLE III: FAILURE RATE PARAMETERS (IF THE RELIABILITY OF OTHER EQUIPMENT AND THE SYSTEM IS 1 WITHOUT ANY FAILURE)

\begin{tabular}{lccc}
\hline \hline Parameter & Phase 1 & Phase 2 & Phase 3 \\
\hline$\lambda_{i}^{A} / h^{-1}$ & 0.010 & 0.060 & 0.012 \\
$\lambda_{i}^{B} / h^{-1}$ & 0.012 & 0.085 & 0.015 \\
$\lambda_{i}^{C} / h^{-1}$ & 0.010 & 0.070 & 0.015 \\
$\lambda_{i}^{D} / h^{-1}$ & 0.015 & 0 & 0 \\
$\lambda_{i}^{E} / h^{-1}$ & 0.002 & 0.0060 & 0.025 \\
$\lambda_{i}^{F} / h^{-1}$ & 0.0018 & 0.0077 & 0.035 \\
$\lambda_{i}^{G} / h^{-1}$ & 0.012 & 0.060 & 0.012 \\
\hline \hline
\end{tabular}

Note: $\lambda_{i}^{A} / h^{-1}$ is the failure rate of batteries, $\lambda_{i}^{B} / h^{-1}$ is the failure rate of high-pressure gas cylinder, $\lambda_{i}^{C} / h^{-1}$ is the failure rate of water pump, $\lambda_{i}^{D} / h^{-1}\left(\lambda_{i}^{E} / h^{-1}\right)$ is the failure rate of water supply (drainage) controller, $\lambda_{i}^{F} / h^{-1}$ is the failure rate of exhaust controller, and $\lambda_{i}^{G} / h^{-1}$ is the failure rate of pressure sensor

TABLE IV: EQUIPMENT PARAMETERS

\begin{tabular}{cccc}
\hline \hline Parameter & $V / \mathrm{cm}^{3}$ & $m / \mathrm{kg}$ & $C$ \\
\hline Equipment A & $48 \times 10^{3}$ & 45 & 20 \\
Equipment B & $22 \times 10^{3}$ & 15 & 8 \\
Equipment C & $32 \times 10^{3}$ & 5 & 2 \\
Equipment D & $0.5 \times 10^{3}$ & 1 & 1 \\
Equipment E & $0.5 \times 10^{3}$ & 1 & 1 \\
\hline
\end{tabular}

\begin{tabular}{cccc}
\hline Equipment F & $0.8 \times 10^{3}$ & 0.5 & 3 \\
Equipment G & $0.3 \times 10^{3}$ & 0.5 & 4 \\
System Constraint & $300 \times 10^{3}$ & 200 & 90 \\
\hline \hline
\end{tabular}

After technical improvement, this system can be put into reliability analysis and its mission profile and reliability block diagram are constructed. The reliability of the submarine free-running model system after technical improvement is estimated to be 0.998 [10]. The estimation of reliability proves that the reliability of the system is improved but still fails to satisfy the requirements.

\section{B. Redundancy Optimization}

Considering that the reliability of the submarine free-running model system still fails to satisfy the requirements after technical improvement, this paper carries out the redundancy optimization for the system to improve its reliability. Since the submarine free-running model system is an automatic navigation model, the parallel redundancy optimization with good feasibility and reliability is more suitable for its redundancy design.

\section{1) The reliability parallel redundancy model of free-running model is constructed as follows}

$$
P_{\phi_{s}}=P_{\phi_{3} A} \times P_{\phi_{3} B} \times P_{\phi_{3} C} \times P_{\phi_{1} D} \times P_{\phi_{3} G} \times P_{\phi_{3} E} \times P_{\phi_{3} F}
$$

Note: $P_{\phi_{s}}$ is system reliability; $P_{\phi X}$ is the reliability of redundant module in the equipment $\mathrm{X}$ in the phase $i$; $\mathrm{A}$ is batteries; $\mathrm{B}$ is high-pressure gas cylinder; $\mathrm{C}$ is water pump; $\mathrm{D}$ is water supply controller; $\mathrm{F}$ is drainage controller; $\mathrm{F}$ is exhaust controller; $\mathrm{G}$ is pressure sensor.

The formula of reliability redundancy is utilized to determine the reliability of redundant module in the equipment $\mathrm{X}$ in the phase $i$.

The reliability of redundant module for batteries $\mathrm{A}$ is calculated as follows:

$$
\begin{aligned}
& P_{\phi_{3} A}=\left[1-\left(1-e^{-\lambda_{\phi_{1} A} t_{1}}\right)^{m_{\phi_{1} A}+1} \times \sum_{k_{\phi_{1} A}=0}^{m_{\phi_{1} A}+1}\left[1-\left(1-e^{-\lambda_{\phi_{2} A} t_{2}}\right)^{m_{\phi_{1} A}-k_{\phi_{1} A}+1}\right]\left(e^{-\lambda_{\phi_{1} A} t_{1}}\right)^{m_{\phi_{1} A}-k_{\phi_{1} A}+1}\left(1-e^{-\lambda_{\phi_{1} A} t_{1}}\right)^{k_{\phi_{1} A}} C_{m_{\phi_{1} A}+1}^{k_{\phi_{1} A}}\right. \\
& \times \sum_{k_{\phi_{2} A}=0}^{m_{\phi_{1} A}-k_{\phi_{1} A}+1}\left[1-\left(1-e^{-\lambda_{\phi_{3} A} t_{3}}\right)^{m_{\phi_{1} A}-k_{\phi_{1} A}-k_{\phi_{2} A}+1}\right]\left(e^{-\lambda_{\phi_{2} A} t_{2}}\right)^{m_{\phi_{1} A}-k_{\phi_{1} A}-k_{\phi_{2} A}+1}\left(1-e^{-\lambda_{\phi_{2} A} t_{2}}\right)^{k_{\phi_{2} A}} C_{m_{\phi_{1} A} A}^{k_{\phi_{2} A}}-k_{\phi_{1} A}+1
\end{aligned}
$$

Similarly, the reliability of redundant module in equipment $\mathrm{B}, \mathrm{C}, \mathrm{D}, \mathrm{E}, \mathrm{F}$ and $\mathrm{G}$ is calculated and substituted into the system reliability redundancy model to calculate the redundancy reliability of the system $P_{\phi_{s}}$. This is detailed in

Reference [10].

\section{2) Redundancy optimization model}

The system redundancy design for improving system reliability is actually a different form of reliability distribution. This method is effective and feasible, but subject to a hidden trouble that if the incorrect number of redundant units is added, it may find it impossible to satisfy all the system constraints (system cost, system volume, system weight and system reliability). Facing this trouble, this paper follows the concept of satisfaction to build a system redundancy optimization model, in order to guarantee the maximization of system reliability. Meanwhile, this can keep the system within the range of other constraints, so as to achieve the most satisfying effect of redundancy optimization.

After combining Table III and Table IV, a redundancy optimization model subject to four factors, namely, system 
reliability constraint, system volume constraint, system weight constraint and system cost constraint, is established based on the missions and structure of the submarine free-running model system. The model is as follows:

$$
\left\{\begin{array}{l}
\max \quad F=0.4615 P+0.1538 V+00.1538 m+0.2308 C \\
f(P)=\left\{\begin{array}{l}
P_{\phi_{s}}, P_{\phi_{s}} \geq 0.995 \\
0, P_{\phi_{s}} \leq 0.995
\end{array}\right. \\
f(V)=\left\{\begin{array}{l}
1,48000 x_{A}+22000 x_{B}+32000 x_{C}+500 x_{D}+500 x_{E}+800 x_{F}+300 x_{G} \leq 300 \times 10^{3} \\
0,48000 x_{A}+22000 x_{B}+32000 x_{C}+500 x_{D}+500 x_{E}+800 x_{F}+300 x_{G}>300 \times 10^{3}
\end{array}\right. \\
f(m)=\left\{\begin{array}{l}
1,45 x_{A}+15 x_{B}+5 x_{C}+x_{D}+x_{E}+0.5 x_{F}+0.5 x_{G} \leq 200 \\
0,45 x_{A}+15 x_{B}+5 x_{C}+x_{D}+x_{E}+0.5 x_{F}+0.5 x_{G}>200
\end{array}\right. \\
f(C)=\left\{\begin{array}{c}
1,20 x_{A}+8 x_{B}+2 x_{C}+x_{D}+x_{E}+3 x_{F}+4 x_{G} \leq 90 \\
C_{0} / C, 20 x_{A}+8 x_{B}+2 x_{C}+x_{D}+x_{E}+3 x_{F}+4 x_{G}>90
\end{array}\right.
\end{array}\right.
$$

TABLE V: RELIABILITY OPTIMIZATION OF THE SUBMARINE FREE-RUNNING MODEL SYSTEM

\begin{tabular}{|c|c|c|c|c|c|c|}
\hline & Preliminary Design & & Technical Improvement & & Redundancy Optimization & \\
\hline \multirow{6}{*}{$\begin{array}{l}\text { Equipment } \\
\text { to } \mathrm{Be}\end{array}$} & AC servo drive & 4 & DC servo drive & 4 & DC servo drive & 4 \\
\hline & Water tank & 4 & Torque controller & 1 & Torque controller & 1 \\
\hline & 45L water tank ballast & 1 & $100 \mathrm{~L}$ water tank ballast & 1 & $100 \mathrm{~L}$ water tank ballast & 1 \\
\hline & $75^{\circ}$ acoustic positioning device & 30 & $100^{\circ}$ acoustic positioning device & 30 & $100^{\circ}$ acoustic positioning device & 30 \\
\hline & Batteries & 1 & Batteries & 1 & Batteries & 2 \\
\hline & High-pressure gas cylinder & 1 & High-pressure gas cylinder & 1 & High-pressure gas cylinder & 2 \\
\hline \multirow[t]{4}{*}{ Optimized } & Water pump & 1 & Water pump & 1 & Water pump & 3 \\
\hline & Water supply controller & 1 & Water supply controller & 1 & Water supply controller & 5 \\
\hline & Exhaust controller & 1 & Exhaust controller & 1 & Exhaust controller & 2 \\
\hline & Pressure sensor & 1 & Pressure sensor & 1 & Pressure sensor & 2 \\
\hline
\end{tabular}

Description: In Equation (3), the value of the comprehensive optimum $F$ is between $[0,1]$, in which 0 stands for dissatisfaction and 1 stands for the highest satisfaction. Thus, if the value of the target function $F$ is closer to 1 , the effect of optimization is more satisfying. $f(p)$, $f(p), f(V), f(m)$, and $f(C)$, are the single-objective optimal functions for four constraints. If reliability satisfies the requirements, it is the final reliability. If it fails to satisfy the requirements, the optimal value is 0 , and the optimal value of other constraints within the specified range is 1 , or it is 0 . The weight coefficients of constraints $(\mathrm{P}, \mathrm{V}, \mathrm{m}, \mathrm{C})$ are 0.2976, $0.2261,0.2261$ and 0.2502 , respectively. The value is between $[0,1]$, and the sum of the weight coefficients of all factors must be 1 . The weights of factors can be determined by employing the AHP method [11].

\section{3) Particle swarm optimization algorithm}

There are lots of algorithms for intelligent optimization. This paper employs the particle swarm optimization algorithm suitable for solving the problems in engineering design to calculate the reliability of the system after redundancy optimization. This algorithm is featured by good adaptability to variables and good ability of global optimization. The particle swarms with 20 particles and 7 particles are selected. It has 100 evolutionary generations and acceleration constants $c 1=1.4$ and $c 2=1.4$. The algorithm obtains the optimization results after 100 random computations. The Fig. 5 presents the iterative diagram after optimization. Obviously, the comprehensive satisfaction is stabilized at 0.9995 after 38 iterations.

The results of parallel redundancy reliability optimization for the submarine free-running model test system are as follows: 1 for equipment $\mathrm{A}, 1$ for equipment $\mathrm{B}, 4$ for equipment $\mathrm{C}, 3$ for equipment $\mathrm{D}, 1$ for equipment $\mathrm{E}, 1$ for equipment $\mathrm{F}$ and 2 for equipment $\mathrm{G}$; system reliability is 0.9998 .

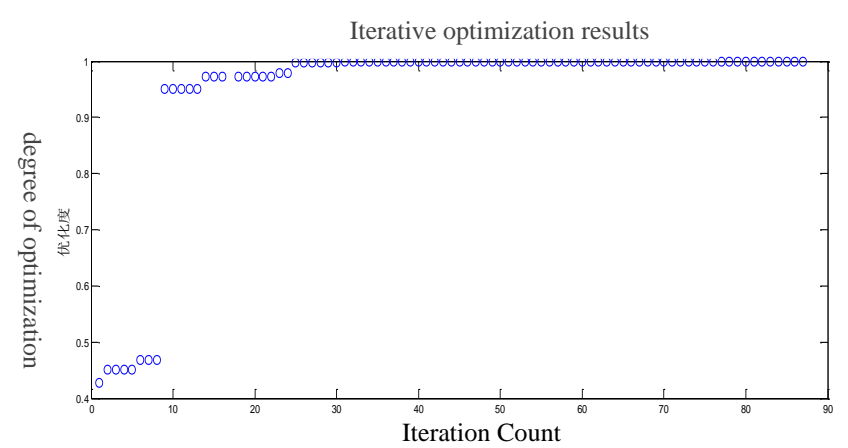

Fig. 5. Diagram or optımızation structure.

\section{RESULT}

The optimization results reveal that the submarine free-running model test system improves its reliability of 0.753 to 0.9998 after technical improvement and redundancy optimization subject to volume, weight and cost constraints. The final reliability satisfies the requirement for 0.995(illustration in Table V). This proves that reliability optimization is feasible and effective for the submarine free-running model system.

\section{CONCLUSION}

This paper carries out the reliability optimization design of 
free-running model subject to the parallel design conditions. In the practical process, submarine free-running model test system is more and more complicated, so we will further take into account vote redundancy and standby redundancy, etc. in the future.

\section{REFERENCES}

[1] M. Alam and M. S. Ubaid, "Titative reliability evaluation of repairable phased-mission systems using Markova approach," Transactions on Reliability, vol. 35, no. 5, pp. 498-503, 1986

[2] W. Kuo, V. R. Prasad, F. A. Tillman, and C. L. Hwang, Optimization Reliability Design: Basic and Clinical, Beijing: Science Press, 2011.

[3] J. Yu, T. Hu, and J. J. Yang, "Reliability parallel redundancy optimization model of phased-mission systems," Fire Control \& Command Control, vol. 18, pp. 26-32, 2011,

[4] J. Yu, T. Hu, and J. J. Yang. "Reliability redundancy optimization model of phased mission systems based on desirability function," Fire Control \& Command Control, vol. 37, pp. 159-163, 2012.

[5] S. P. Chew, S. J. Dunnett, and J. D. Andrews, "Phased mission modelling of systems with maintenance-free operating periods using simulated Petri nets," Reliability Engineering and System Safety, vol. 93, pp. 980-994,2008.

[6] GJB450A, General Requirements for Equipment Reliability, Beijing: National Defense Industry Press, 1990

[7] S. K. Zeng,T. D. Zhao, and J. G. Zhang, A Course of System Reliability Design Analysis, Beijing: Beihang University Press, 2001

[8] S. Y. Wang, Failure Mode and Effect Analysis (FMEA), Guangzhou: Zhongshan University Press, 2003.
[9] S. X. Zhou and Z. Q. Wang, "Calculation of Warship System Redundancy Optimization Based on Reliability," China Water Transport, vol. 2, pp. 46-47, 2007.

[10] S. Q. Liu, "Reliability Optimization Design of Submarine Free-running Model System," Naval University of Engineering, Wuhan, China, 2011.

[11] J. Yu, "Study on Reliability Redundancy Optimization of Phased Mission System," Naval University of Engineering, Wuhan, China, 2010.

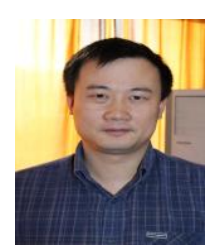

J. J. Yang was born in China in 1979. He received his Ph.D. in system engineering from Navy University of Engineering, Wu Han, China in 2011. Dr. Yang is currently an associate professor of Department of Management Science at Naval University of Engineering. $\mathrm{He}$ has performed and directed research on the complex systems. development and application of reliability analyses of

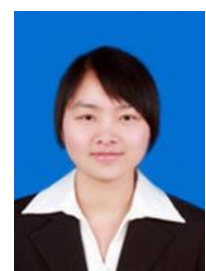

W. J. Li was born in China in 1991. She is currently a postgraduate student in management science and engineering, Navy University of Engineering, Wu Han, China. 